\title{
Publisher Correction: Pelagic barite precipitation at micromolar ambient sulfate
}

\author{
Tristan J. Horner (10 1,2, Helena V. Pryer ${ }^{1,2,3}$, Sune G. Nielsen (10) 1,3, Peter W. Crockford ${ }^{4}$, Julia M. Gauglitz ${ }^{2}$, \\ Boswell A. Wing 5 \& Richard D. Ricketts ${ }^{6}$
}

Correction to: Nature Communications https://doi.org/10.1038/s41467-017-01229-5, Article published online 07 November 2017

The original version of this Article contained an error in the barite saturation state equation in the fourth paragraph of the Introduction and incorrectly read ' $\left.\Omega_{\text {barite }}=\left(\left\{{ }^{134} \mathrm{Ba}^{2+}\right\} \cdot\left\{\mathrm{SO}_{4}^{2-}\right\}\right) / K_{\mathrm{sp}}\right)$ '. The correct version removes the superscript 134 next to 'Ba ${ }^{2+}$ '. This error has now been corrected in both the PDF and HTML versions of the Article.

Published online: 16 January 2018

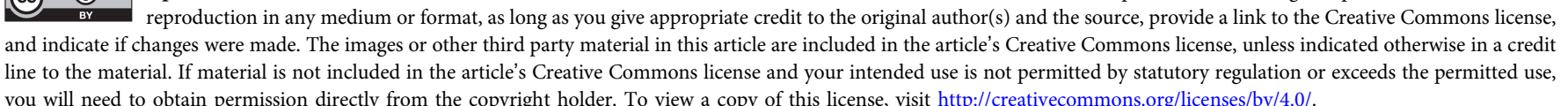
you will need to obtain permission directly from the copyright holder. To view a copy of this license, visit http://creativecommons.org/licenses/by/4.0/.

(C) The Author(s) 2018

\footnotetext{
${ }^{1}$ NIRVANA Laboratories, Woods Hole Oceanographic Institution, Woods Hole, MA 02543-1050, USA. ${ }^{2}$ Department of Marine Chemistry and Geochemistry, Woods Hole Oceanographic Institution, Woods Hole, MA 02543-1050, USA. ${ }^{3}$ Department of Geology and Geophysics, Woods Hole Oceanographic Institution, Woods Hole, MA 02543-1050, USA. ${ }^{4}$ Department of Earth and Planetary Sciences, McGill University, Montreal, QC, Canada H3A OE8. ${ }^{5}$ Geological Sciences, University of Colorado Boulder, Boulder, CO 80309, USA. ${ }^{6}$ Large Lakes Observatory, University of Minnesota Duluth, Duluth, MN 55812, USA. Correspondence and requests for materials should be addressed to T.J.H. (email: Tristan.Horner@whoi.edu)
} 